\begin{tabular}{|c|c|}
\hline Title & A berration-corrected focused ion beam for time of-flight secondary neutral mass spectrometry \\
\hline Author(s) & $\begin{array}{l}\text { Nagata, Kosuke; Bajo, Ken-ichi; Itose, Satoru; Matsuya, Miyuki; Ishihara, Morio; Uchino, Kiichiro; Y urimoto, } \\
\text { Hisay oshi }\end{array}$ \\
\hline Citation & $\begin{array}{l}\text { A pplied Phy sics Express (A PEX ), 12(8), } 085005 \\
\text { https://doi.org/10.7567/1882-0786/ab30e4 }\end{array}$ \\
\hline Issue Date & 2019-08-01 \\
\hline Doc URL & http:/hdl.handle.net/2115/8865 \\
\hline Type & article (author version) \\
\hline File Information & A ppl. Phys. Express_12(8)_085005.pdf \\
\hline
\end{tabular}

Instructions for use 


\section{Aberration-corrected focused ion beam for time-of-flight secondary neutral mass spectrometry}

Kosuke Nagata ${ }^{1}$, Ken-ichi Bajo ${ }^{1}$, Satoru Itose ${ }^{2}$, Miyuki Matsuya ${ }^{2}$, Morio Ishihara $^{3}$, Kiichiro Uchino $^{4}$, and Hisayoshi Yurimoto ${ }^{1,5 *}$

${ }^{1}$ Natural History Sciences, IIL, Hokkaido University, Sapporo 001-0021, Japan

${ }^{2} J E O L$ Ltd., Musashino, Akishima, Tokyo 196-8558, Japan

${ }^{3}$ Department of Physics, Osaka University, Toyonaka, Osaka 560-0043, Japan

${ }^{4}$ Graduate School of Engineering Sciences, Kyushu University, Kasuga, Fukuoka

816-8580, Japan

${ }^{5}$ ISAS/JAXA, Sagamihara 252-5210, Japan

E-mail: yuri@ep.sci.hokudai.ac.jp

A chromatic and spherical aberration corrector with liquid $\mathrm{Ga}$ ion metal source was developed. The aberration corrector reduced the ion probe diameter to $\sim 1.5$ times smaller for the ${ }^{69} \mathrm{Ga}^{+}$beam in aberration correction mode compared with the corrector in non-aberration correction mode. The probe current at a given probe size is approximately two times larger in aberration correction mode than in non-aberration correction mode. The aberration-corrected focused ion beam yields higher lateral resolutions and higher sensitivities with lower acceleration voltage for the same acquisition time down to $10 \mathrm{~nm}$ with a current of $1 \mathrm{pA}$. 
Imaging of secondary ion mass spectrometry (SIMS) is a useful analytical method to determine three-dimensional spatial distribution for trace elements and isotopes in solid samples. This method has been applied widely to various scientific fields from material science to biology and geochemistry. To achieve a high spatial resolution of nanometers, focused ion beams by using the liquid metal ion sources (LMIS) have been applied as primary beams. ${ }^{1,2,3,4,5,6)}$ A pioneering work of Levi-Setti et al. ${ }^{7}$ demonstrated that $20 \mathrm{~nm}$ lateral resolution can be achieved for imaging SIMS using $\mathrm{Ga}^{+}$-probe from LMIS. This resolution, which remains one of the best data, is similar to a broadening estimated from an ion spattering theory on a solid surface by ion-probe of $\mathrm{keV}$ energy. ${ }^{8,9)}$ However, applications of $\mathrm{Ga}^{+}$-probe to imaging SIMS have been limited because secondary ion yields are more than two orders of magnitude lower under Ga bombardment compared with those under $\mathrm{O}$ or $\mathrm{Cs}$ bombardments for most elements of many materials. ${ }^{10,11)}$

Recently there have been developments in secondary neutral mass spectrometry (SNMS) with strong-field tunneling post-ionization. ${ }^{12,13,14,15)}$ A laser ionization mass nanoscope (LIMAS) ionized sputtered secondary neutrals $\sim 100 \%$ (except He which yielded $\sim 70 \%$ ) by irradiation of high power femto-second laser. ${ }^{13,16,17)}$ Consequently, a useful yield improves to $0.2 \%$ at mass resolution $(M / \Delta M)$ of 600000 (full width at half maximum, FWHM) for Si. ${ }^{18)}$ This yield is almost comparable to conventional SIMS of $0.7 \%$ under $M / \Delta M=500^{19)}$ and the low secondary ion yield from the Ga primary beam has not caused weakness in SNMS imaging.

Because of an intrinsic energy spread $(5-10 \mathrm{eV})$ of the ions extracted from LMIS ${ }^{20,21)}$, chromatic aberration of the primary beam optics limits the probe size and current. The chromatic and spherical aberrations can be eliminated by an electrostatic corrector that is suitable for ion beam optics. ${ }^{22,23,24,25,26,27)}$ The aberration corrector was developed and is installed in LIMAS. ${ }^{13,28,29)}$ They demonstrated the potential to improve the spatial resolution of an ion-induced secondary electron (SE) image.

Here we studied the performance of the chromatic and spherical aberration corrector and spatial resolution of ion images of LIMAS.

Figure 1A shows an overview of the primary column of LIMAS. A focused ion beam (FIB) system with a $\mathrm{Ga}^{+}$liquid-metal ion source (LMIS) is equipped with an aberration corrector which is composed of eight electrostatic dodecapoles (Figs. 1B and 1C), initially designed by Weißbäcker and Rose. ${ }^{25,26)}$ The dodecapoles produce dipole, quadrupole, hexapole and octupole fields, which are controlled by a graphical user interface on a personal computer. The effects of the correction and residual aberrations could be verified 
from the beam shapes by taking the ion-induced secondary electron (SE) images under- and over-focus. ${ }^{30)}$ The semiautomatic aberration correction procedure assisted the fine-tuning of the optics; this method was significantly useful because the ion beam irradiation was changing the topography of the specimen surface in the alignment procedure. The chromatic aberration was evaluated by changing the accelerating voltage while keeping the optical conditions such as applied voltages for lenses and deflectors. The spherical aberration was evaluated by shifting an aperture to a given direction from the right position.

Optical conditions are optimized for both cases in which the corrector is turned on and off as shown in Figs. 1C and D. Operating parameters for the aberration corrector were stored in a control computer for each accelerating voltage and probe current. The corrector can correct both spherical and chromatic aberrations, and the diameter of the ion probe is decreased theoretically to about $1 / 2-1 / 3$ by the corrector over the probe current ranges $1 \mathrm{pA}$ $-10 \mathrm{nA}$.

We used LIMAS, an SNMS instrument, at Hokkaido University 13,18,28,31) for our measurements and continuous primary ion probes of ${ }^{69} \mathrm{Ga}^{+}(20 \mathrm{keV}$ and $1-500 \mathrm{pA})$ to obtain secondary electron (SE) images. Dwell times at each pixel were variable depending on SE intensities from 16 to $65 \mu \mathrm{s}$. The primary beam was rastered over a pattern of $1280 \times 960$ pixels and the elapsed time for the image area was from 20 to $80 \mathrm{~s}$. The pixel sizes were adjusted depending on the probe diameters used.

To obtain ion images by ion-induced secondary neutral mass spectrometry (known as SNMS images), we used primary ion probes of ${ }^{69} \mathrm{Ga}^{+}(20 \mathrm{keV}$ and $1-400 \mathrm{pA})$ with pulses to $200 \mathrm{~ns}$ width. Sputtered neutrals were ionized with $1 \mathrm{kHz}$ repetition by a focused $(50 \mu \mathrm{m}$ diameter at the laser axis position of $100 \mu \mathrm{m}$ above sample surface) femtosecond laser beam under a strong-field ionization condition. We accumulated post-ionized ions for 25-200 primary beam pulses at each pixel to collect data. The primary beam was rastered on the sample over a pattern of $128 \times 128$ or $150 \times 150$ pixels with a step interval depending on the probe diameters used. The dwell times at each pixel were variable depending on the ion intensities from 25 to $200 \mathrm{~ms}$. The elapsed time for an image was from 563 to $3222 \mathrm{~s}$. Measurement conditions are summarized in Table S1 (see supplementary data).

We have verified the focused beam shapes at a given current by time variations of sputter crater shapes irradiated on Si wafer. A primary beam without aberration correction at a current of $30 \mathrm{nA}$ shows a large shallow halo surrounding focused deep crater, whereas, under the same beam current and sputter time, a primary beam with aberration correction shows no visible halo and a smaller and deeper crater; this variance suggests that aberration correction 
yields smaller beam size and higher beam density. ${ }^{28)}$

Focused primary beams with and without aberration correction at a current of $3 \mathrm{pA}$ with acceleration voltage of $20 \mathrm{kV}$ were used for the evaluation of probe shape distribution. The sputtering crater forms a deep crater in the center and surrounding halo crater (Figs. S1 and S2; see supplementary data). The diameters of deep and halo craters would correspond to Gaussian and total beam sizes at a given sputter time, respectively. The beam intensity distribution along radial directions would be determined by diameter variations as a function of the inverse of sputter time (Fig. 2). The intensity distributions of the deep crater are approximated by the Gaussian distribution function with the standard deviation $\sigma$. The beam diameter $2 \sigma$ is $11.7 \mathrm{~nm}$ with aberration correction and $20.2 \mathrm{~nm}$ without aberration correction. The corrector causes the diameter of the ion probe to decrease to $1 / 1.7$, which is close to the theoretical estimation $(1 / 2-1 / 3)$.

The intensity profile for aberration correction begins to depart from Gaussian distribution at $2 \%$ of peak to show halo distribution. Characteristics of the intensity profile for non-aberration correction are similar, but the halo begins at $5 \%$ of peak. The halo is smaller with aberration correction than without aberration correction. The difference demonstrates that the aberration corrector reduces the ion optical aberration and consequently, the beam densities increase.

A relationship between primary ion current and probe diameter is evaluated by lateral spatial resolutions of SE images of Sn particles on a graphite substrate (Fig. 3). The lateral resolution is defined by the knife-edge method, i.e., the 16-84\% criterion, on a sharp Sn particle side. This criterion is equivalent to the $2 \sigma$ criterion for the probe diameter of the Gaussian probe shown in Fig. 2. The lateral resolution using $3 \mathrm{pA}$ probe is $12 \mathrm{~nm}$ in aberration correction mode and $17 \mathrm{~nm}$ in non-correction mode (Fig. 3). These values are equivalent with the probe diameter defined by the sputter crater method. Therefore, the probe diameter can be determined by the lateral resolution of SE image. The probe diameter at a given probe current is approximately 1.4 times smaller in aberration correction mode than in non-correction mode over the probe current ranges $1 \mathrm{pA}-1 \mathrm{nA}$ and down to $10 \mathrm{~nm}$ at 1 pA (Fig. 4). In other words, the probe current at a given probe diameter is about two times larger with aberration correction than without aberration correction.

The aberration corrector works efficiently to produce fine and dense ion beam probes; therefore, correction of the chromatic and spherical aberrations may enable a mass analysis of small particles or fine structures on a specimen surface with sizes of $10 \mathrm{~nm}$. Lateral resolutions of the SNMS image, however, are lower than the probe diameter at a given probe 
current and are essentially the same either in aberration correction mode or in non-correction mode (Fig. 4).

The mechanical vibration of the sample stage cause jitters measuring approximately 20 $\mathrm{nm}$ to appeare at the edges of Sn particles of the SE images of Fig. 3. The dwell time at a pixel for SNMS imaging (25-200 ms) is much longer than those for the SE imaging (16-65 $\mu \mathrm{s})$. The vibration was averaged and incorporated into several pixels and consequently, the jitters disappeared in the SNMS images (Fig. 3) and the lateral resolutions decreased. Consequently, the highest lateral resolution of SNMS image is limited to approximately 20 $\mathrm{nm}$ under both with and without aberration correction (Fig. 4). The probe diameters (lateral resolutions) determined by SE images are always smaller than those determined by SNMS images. The differences of the probe diameters increase from $10 \mathrm{~nm}$ to $40 \mathrm{~nm}$ when probe currents also increase (Fig. 4). The differences are not caused by modification of sample surface by sputtering because irradiated ion numbers at a pixel are larger for the SE image than for SNMS images under the same probe current (Table S1; see supplementary data). The differences are not caused by sample stage drift or beam drift because the dwell time at a pixel becomes shorter among the SNMS images with increasing probe currents. The SE images determined the probe diameters, however the lateral resolutions of SNMS images were approximately half the size of the probe diameters. Further study is necessary to clarify reasons for the difference.

The Cameca NanoSIMS is a commercial SIMS designed to act as a high lateral resolution image of nanometer scale resolution. ${ }^{32)}$ Probe current at a given lateral resolution is fifty to one hundred times higher in the SNMS image than in the nanoSIMS image used by radio frequency $\mathrm{O}^{-}$plasma source and thermal ionization $\mathrm{Cs}^{+}$source (Fig. 4). Lateral resolution of the UC-HRL SIMS image, which are one of the highest resolution images established by SIMS, ${ }^{7}$ is comparable to that of the SNMS image at a given probe current although the acceleration voltage was set to $40 \mathrm{kV}$ for the UC-HRL SIMS and $20 \mathrm{kV}$ for the LIMAS SNMS. Thus, the higher current density with lower acceleration voltage is provided by the aberration-corrected focused ion beam to allow the reduction of the probe size to achieve a higher lateral resolution. The smallest probe diameter produced with the aberration corrected focused ion beam was $10 \mathrm{~nm}$ with a current of $1 \mathrm{pA}$ of ${ }^{69} \mathrm{Ga}^{+}$primary ions at an impact energy of $20 \mathrm{keV}$.

The aberration-corrected focused ion beam with a probe current of $400 \mathrm{pA}$ was applied to the localization of carbon isotopes in chromosomes during cell division of HeLa cells (Fig. 5). HeLa cells enriched in ${ }^{13} \mathrm{C}$ isotope were cultured in a growth medium of natural $\mathrm{C}$ isotope 
abundance. DNA replication forms sister chromatids with less ${ }^{13} \mathrm{C}$-enriched isotopic composition. Pairs of ${ }^{13} \mathrm{C}$-enriched and less ${ }^{13} \mathrm{C}$-enriched sister chromatids appeared in a daughter cell at the second cell division of mitosis (Fig. 5C). The lateral resolution of the image is $100 \mathrm{~nm}$, which is evaluated by the adhesion boundary between the sister chromatid pair (Fig. 5C). The lateral resolution is improved about $40 \mathrm{~nm}$ more than that of the SNMS image inferred from Sn particle samples, and is consistent with the probe diameter observed by aberration-corrected SE image (Fig. 4, Table S1).

In conclusion, a chromatic and spherical aberration corrector was developed and installed in a primary ion column of SNMS instrument LIMAS. The probe size of ${ }^{69} \mathrm{Ga}^{+}$ beam was focused $\sim 1.5$ times smaller by the corrector compared with the case of not using the corrector at a given probe current over ranges from $1 \mathrm{pA}$ to $1 \mathrm{nA}$. The probe current at a given probe size is about two times larger with aberration correction than without aberration correction. Thus, the aberration corrector works efficiently to produce fine and dense ion beam probes down to $10 \mathrm{~nm}$ at $1 \mathrm{pA}$ with impact energy of $20 \mathrm{keV}$. The aberration-corrected focused ion beam of ${ }^{69} \mathrm{Ga}^{+}$offers a net improvement on the SNMS imaging in terms of primary beam current density compared to the commonly used LMIS source, which translates in higher lateral resolutions down to $10 \mathrm{~nm}$ and higher sensitivities with lower acceleration voltage for the same acquisition time. The aberration-corrected focused ion beam was applied successfully to the localization of carbon isotopes in chromosomes during cell division of HeLa cells.

\section{Acknowledgments}

This study is supported by JSPS Monka-sho grants. 


\section{References}

1) J. Orloff, J. Vac. Sci. Technol. B 5, 175 (1987).

2) R. Hill, Proc. SPIE 2014, 112 (1993).

3) T. Ishitani and T. Kawanami, J. Vac. Sci. Technol. B 13, 372 (1995).

4) P. Kruit and X. R. Jiang, J. Vac. Sci. Technol. B 14, 1635 (1996).

5) L. Wang, J. Vac. Sci. Technol. B 15, 833 (1997).

6) K. Sakaguchi and T. Sekine, J. Vac. Sci. Technol. B 16, 2462 (1998).

7) R. Levi-Setti, G. Crow, and Y. L. Wang, Scanning Electron Microsc. Pt 2, 535 (1985).

8) R. Levi-Setti, and T. R. Fox, Nucl. Instrum. Methods 168, 139 (1980).

9) T. Sakamoto, M. Koizumi, J. Kawasaki and J. Yamaguchi, Appl. Surf. Sci. 255, 1617 (2008).

10) H. N. Migeon, F. Saldi, Y. Gao, and M. Schuhmacher, Int. J. Mass Spectrom. Ion Processes 143, 51 (1995).

11) P. van der Heide, Secondary Ion Mass Spectrometry, John Wiley \& Sons, Inc., Hoboken, NJ, USA (2014). https://doi.org/10.1002/9781118916780.fmatter.

12) M. Ishihara, S. Ebata, K. Kumondai, R. Mibuka, K. Uchino and H. Yurimoto, Surf. Interface Anal. 42, 1598 (2010).

13) S. Ebata, M. Ishihara, K. Uchino, S. Itose, M. Matsuya, M. Kudo, K. Bajo, and H. Yurimoto, Surf. Interface Anal. 44, 635 (2012).

14) S. Ebata, M. Ishihara, K. Kumondai, R. Mibuka, K. Uchino and H. Yurimoto, J. Am. Soc. Mass Spectrom. 24, 222 (2013).

15) K. Bajo, C. T. Olinger, A. J. G. Jurewicz, D. S. Burnett, I. Sakaguchi, T. Suzuki, S. Itose, M. Ishihara, K. Uchino, R. Wieler and H. Yurimoto, Geochem. J. 49, 559 (2015).

16) R. Mibuka, S. Hassaballa, K. Uchino, H. Yurimoto, R. Todokoro, K. Kumondai and M. Ishihara, Appl. Surf. Sci. 255, 1595 (2008).

17) H. Yurimoto, K. Bajo, I. Sakaguchi, T. T. Suzuki, A. J. G. Jurewicz, S. Itose, K. Uchino, and M. Ishihara, Surf. Interface Anal. 48, 1181 (2016).

18) A. Tonotani, K. Bajo, S. Itose, M. Ishihara, K. Uchino, and H. Yurimoto, Surf. Interface Anal. 48, 1122 (2016).

19) R. L. Hervig, F. K. Mazdaba, P. Williams, Y. Guan, G. R. Huss, and L. A. Leshin, Chem. Geol. 227, 83 (2006).

20) L. W. Swanson, G. A. Schwind, A. E. Bell and J. E. Brady, J. Vac. Sci. Tech. 16, 1864 (1979).

21) A. E. Bell, K. Rao, G. A. Schwind and L. W. Swansonisep, J. Vac. Sci. Technol. B 6, 927 
(1988).

22) C. Weißbäcker and H. Rose, Optik 110, (Suppl. 8), 8 (1999).

23) C. Weißbäcker and H. Rose, Proc. 12th Europ. Congr. Electron Microsc., Brno, vol. 3, I 157 (2000).

24) C. Weißbäcker, Dissertation, TU Darmstadt D17 (2001).

25) C. Weißbäcker, and H. Rose, J. Electron Microsc. 50, 383 (2001).

26) C. Weißbäcker, and H. Rose, J. Electron Microsc. 51, 45 (2002).

27) J. Zach, Proc. 16th Int. Microsc. Congr., Sapporo, Vol 2, 662 (2006).

28) K. Bajo, S. Itose, M. Matsuya, M. Ishihara, K. Uchino, M. Kudo, I. Sakaguchi, and H. Yurimoto, Surf. Interface Anal. 48, 1190 (2016).

29) S. Itose, M. Matsuya, S. Uno, K. Yamashita, S. Ebata, M. Ishihara, K. Uchino, H. Yurimoto, K. Sakaguchi, and M. Kudo, Microsc. Microanal. 17, 654 (2011).

30) S. Uno, K. Honda, N. Nakamura, M. Matsuya, and J. Zach, Optik 116, 438 (2005).

31) K. Bajo, O. Fujioka, S. Itose, M. Ishihara, K. Uchino, and H. Yurimoto, Surf. Interface Anal. 51, 35 (2019).

32) J. Malherbe, F. Penen, M.-P. Isaure, J. Frank, G. Hause, D. Dobritzsch, E. Gontier, F. Horréard, F. Hillion, and D. Schaumlöffel, Anal. Chem. 88, 7130 (2016). 


\section{Figure Captions}

Fig. 1. (A) Aberration corrector (AC) installed in the primary column of LIMAS, (B) Top view of the first dodecapole of the aberration corrector, (C) Schematic ray path for aberration-corrected primary beam by the aberration corrector (AC) composed of eight dodecapoles and (D) Schematic ray path for aberration-uncorrected primary beam. LMIS: liquid metal ion source, CL: condenser lens, AC: aberration corrector, OL: objective lens.

Fig. 2. Radial intensity distribution of $\mathrm{Ga}^{+}$primary beam $(20 \mathrm{keV}, 3 \mathrm{pA})$. Solid symbol: deep crater, open symbol: halo crater, solid line: radial intensity distribution, dashed line: Gaussian function approximation. Original images of sputtering craters are shown in Figs. S1 and S2. The data values are shown in Table S2 (see supplementary data).

Fig. 3. Determination of the lateral resolution obtained from $1100 \times 1100 \mathrm{~nm}^{2}$ field of view of $\mathrm{Sn}$ particles on graphite substrate under $3 \mathrm{pA} \mathrm{Ga}^{+}$probe. Lateral resolutions are calculated from the $16-84 \%$ criterion along a line scan (white line in the image). (A) SE image under aberration correction mode, (B) SE image under non-correction mode, (C) SNMS image under aberration correction mode for combined $\mathrm{Sn}$ isotopes of ${ }^{116} \mathrm{Sn}^{+},{ }^{118} \mathrm{Sn}^{+}$ and ${ }^{120} \mathrm{Sn}^{+}$ions and (D) SNMS image under non-correction mode for combined Sn isotopes of ${ }^{116} \mathrm{Sn}^{+},{ }^{118} \mathrm{Sn}^{+}$and ${ }^{120} \mathrm{Sn}^{+}$ions.

Fig. 4. Probe current density dependent on the lateral resolution (probe diameter). Solid circle: LIMAS SE image under aberration correction mode by $20 \mathrm{keV} \mathrm{Ga}^{+}$probe, open circle: LIMAS SE image under non-correction mode by $20 \mathrm{keV} \mathrm{Ga}^{+}$probe, solid square: LIMAS SNMS image under aberration correction mode by $20 \mathrm{keV} \mathrm{Ga}^{+}$probe, open square: LIMAS SNMS image under non-correction mode by $20 \mathrm{keV} \mathrm{Ga}{ }^{+}$probe, open triangle: UC-HRL SIMS image by $40 \mathrm{keV} \mathrm{Ga}^{+}$probe ${ }^{7)}$, cross: NanoSIMS SIMS image by $20 \mathrm{keV} \mathrm{O}^{-}$probe ${ }^{32)}$, plus: Nano-SIMS SIMS image by $20 \mathrm{keV} \mathrm{Cs}^{+}$probe ${ }^{32)}$. The data values are shown in Table S1 (see supplementary data).

Fig. 5. SE and SNMS images of chromosomes during cell division of a HeLa cell. (A) SE, 
Template for APEX (Jan. 2014)

(B) ${ }^{12} \mathrm{C},(\mathrm{C}){ }^{13} \mathrm{C}$ and (D) line profile along a line shown in C. Field of view: $19 \times 19 \mu \mathrm{m}^{2}$. 
Template for APEX (Jan. 2014)
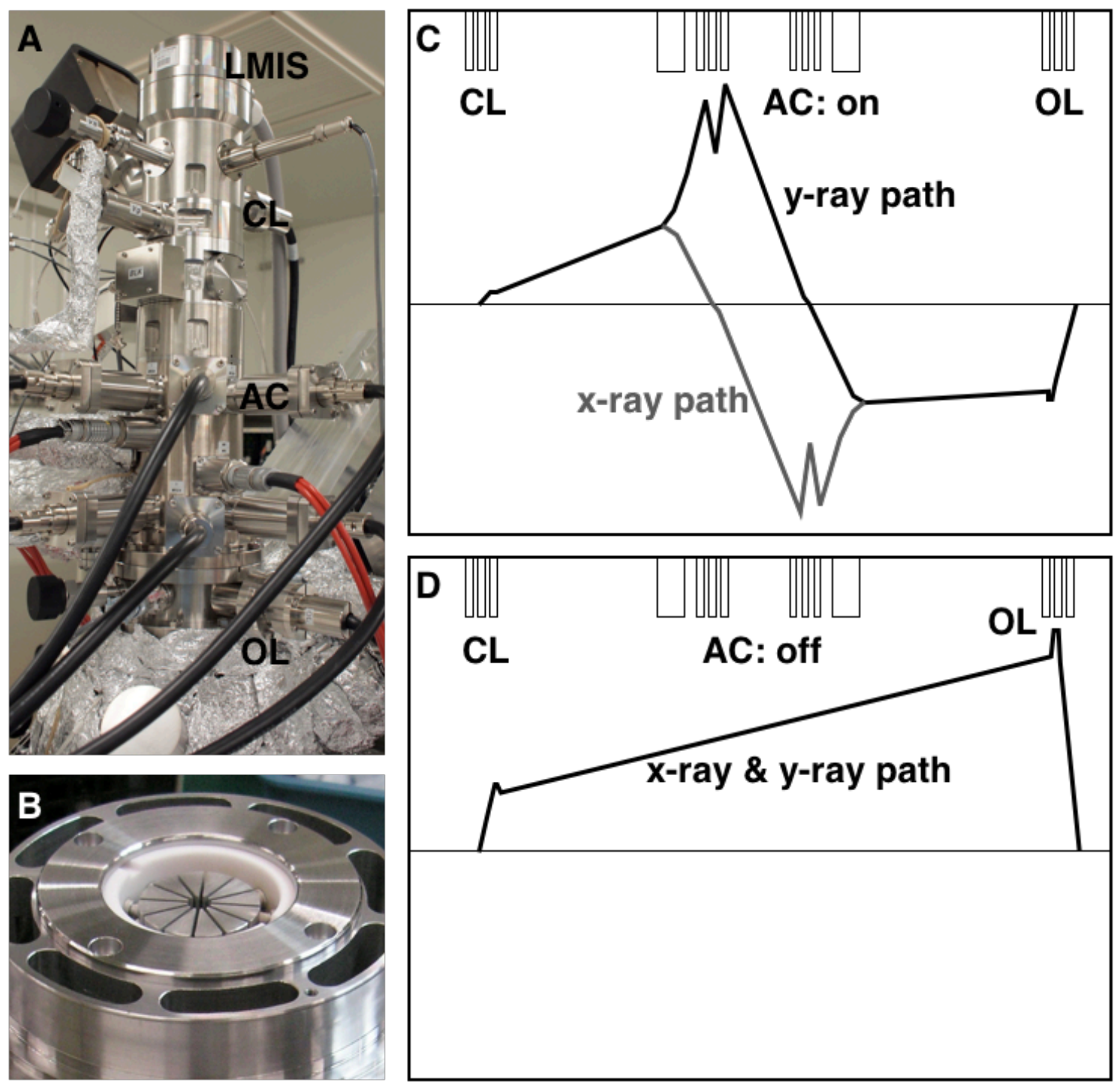

Fig. 1. 
Template for APEX (Jan. 2014)

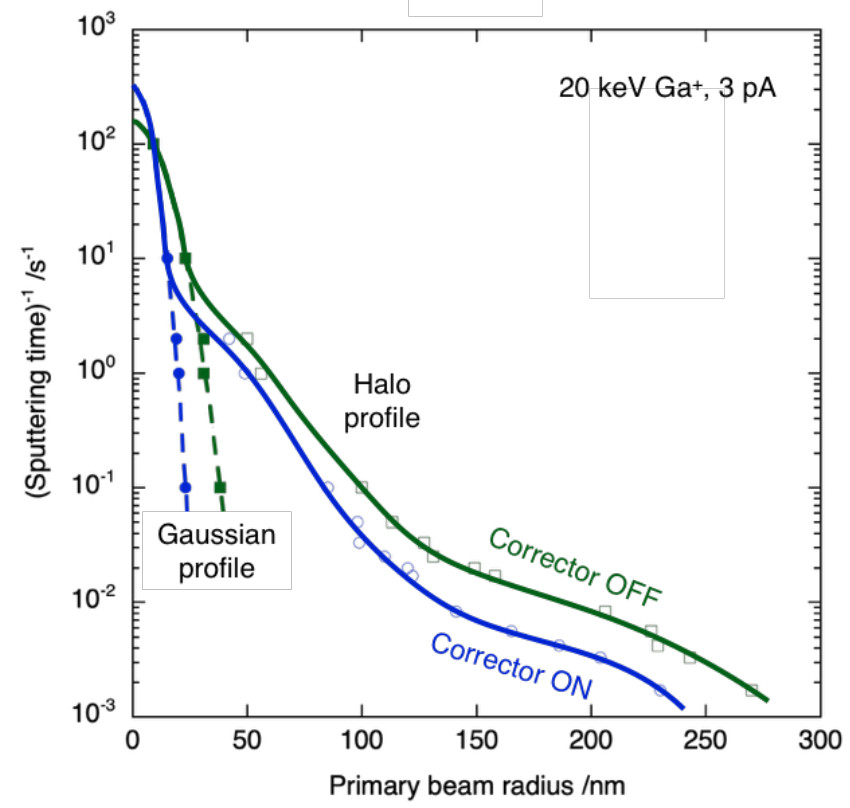

Fig. 2. 
Template for APEX (Jan. 2014)
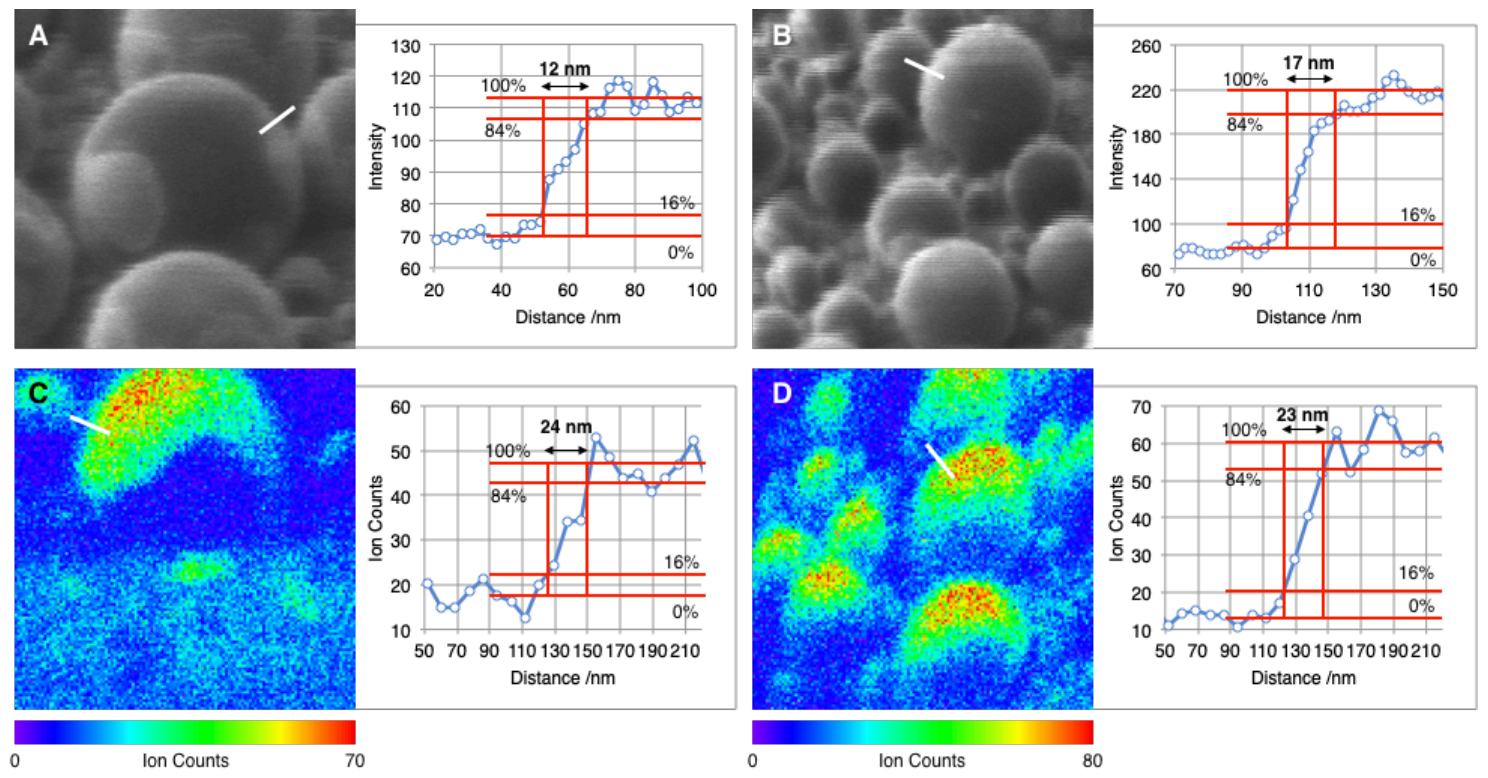

Fig. 3. 
Template for APEX (Jan. 2014)

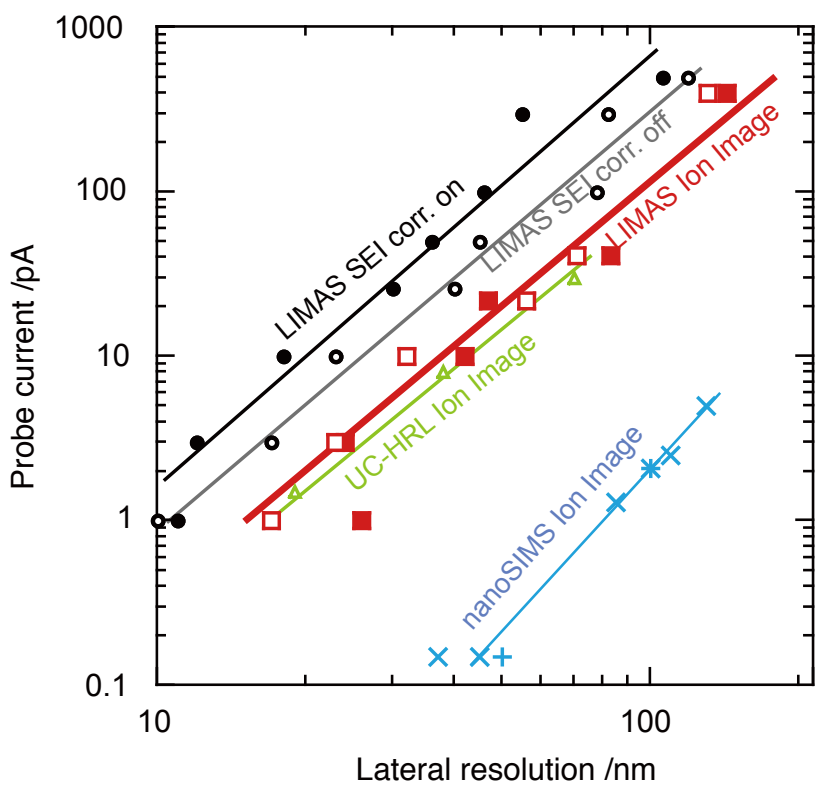

Fig. 4. 
Template for APEX (Jan. 2014)
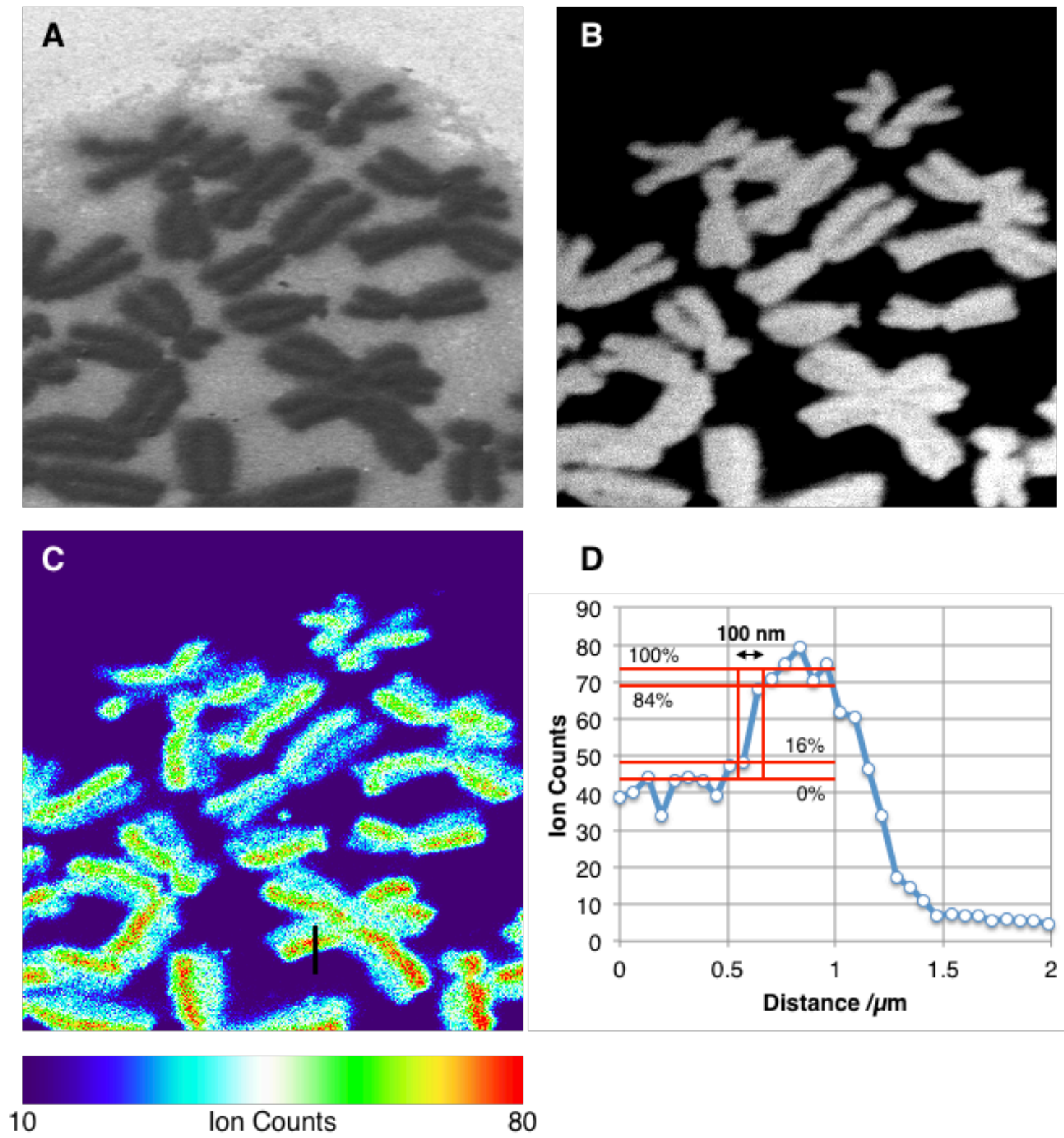

Fig. 5. 
Template for APEX (Jan. 2014)

Table S1. Probe current dependent on the probe diameter (lateral resolution) with the measurement conditions.

\begin{tabular}{|c|c|c|c|c|c|c|c|c|c|c|c|c|c|}
\hline \multirow[b]{2}{*}{ Beam\# } & \multirow{2}{*}{$\begin{array}{c}\text { Pulse } \\
\text { width } \\
\text { (ns) }\end{array}$} & \multirow{2}{*}{$\begin{array}{c}\text { Probe } \\
\text { current } \\
(p A)\end{array}$} & \multicolumn{2}{|c|}{$\begin{array}{c}\text { Probe diameter } \\
(\mathrm{nm})\end{array}$} & \multirow{2}{*}{$\begin{array}{c}\text { Dwell } \\
\text { time/pixel } \\
(\mu \mathrm{s})\end{array}$} & \multirow{2}{*}{$\begin{array}{c}\text { Sputter } \\
\text { time/pixel } \\
(\mu \mathrm{s})\end{array}$} & \multirow[b]{2}{*}{$\begin{array}{l}\text { Irradiated } \\
\text { ions/pixel }\end{array}$} & \multicolumn{2}{|c|}{$\begin{array}{l}\text { Image size } \\
\text { (pixel) }\end{array}$} & \multirow{2}{*}{$\begin{array}{l}\text { Pixel } \\
\text { size } \\
(\mathrm{nm})\end{array}$} & \multicolumn{2}{|c|}{ Image size (nm) } & \multirow{2}{*}{$\begin{array}{c}\text { Elapsed } \\
\text { time } \\
\text { /image } \\
\text { (s) }\end{array}$} \\
\hline & & & $\begin{array}{l}\text { Corr. } \\
\text { ON }\end{array}$ & $\begin{array}{l}\text { Corr. } \\
\text { OFF }\end{array}$ & & & & $\mathrm{H}$ & V & & $\mathrm{H}$ & V & \\
\hline \multicolumn{14}{|c|}{ SE image } \\
\hline Beam13 & $\infty$ & 1 & 11 & 10 & 65 & 65 & 406 & 1280 & 960 & 2.07 & 2650 & 1920 & 80 \\
\hline Beam12 & $\infty$ & 3 & 12 & 17 & 65 & 65 & 1219 & 1280 & 960 & 2.50 & 3200 & 2400 & 80 \\
\hline Beam11 & $\infty$ & 10 & 18 & 23 & 16 & 16 & 1000 & 1280 & 960 & 3.34 & 4270 & 3203 & 20 \\
\hline Beam10 & $\infty$ & 26 & 30 & 40 & 16 & 16 & 2600 & 1280 & 960 & 3.34 & 4270 & 3203 & 20 \\
\hline Beam09 & $\infty$ & 50 & 36 & 45 & 16 & 16 & 5000 & 1280 & 960 & 5.00 & 6400 & 4800 & 20 \\
\hline Beam08 & $\infty$ & 100 & 46 & 78 & 16 & 16 & 10000 & 1280 & 960 & 6.66 & 8530 & 6398 & 20 \\
\hline Beam07 & $\infty$ & 300 & 55 & 82 & 16 & 16 & 30000 & 1280 & 960 & 6.66 & 8530 & 6398 & 20 \\
\hline Beam06 & $\infty$ & 500 & 106 & 119 & 16 & 16 & 50000 & 1280 & 960 & 10.00 & 12800 & 9600 & 20 \\
\hline \multicolumn{14}{|c|}{ SNMS image } \\
\hline Beam13 & 200 & 1 & 26 & 17 & 200000 & 40 & 250 & 128 & 128 & 8.33 & 1066 & 1066 & 3277 \\
\hline Beam12 & 200 & 3 & 24 & 23 & 100000 & 20 & 375 & 128 & 128 & 8.33 & 1066 & 1066 & 1638 \\
\hline Beam11 & 200 & 10 & 42 & - & 100000 & 20 & 1250 & 150 & 150 & 14.23 & 2135 & 2135 & 2250 \\
\hline Beam11 & 200 & 10 & - & 32 & 100000 & 20 & 1250 & 128 & 128 & 15.03 & 1924 & 1924 & 1638 \\
\hline Beam10 & 200 & 22 & 47 & - & 100000 & 20 & 2750 & 128 & 128 & 15.03 & 1924 & 1924 & 1638 \\
\hline Beam10 & 200 & 22 & - & 56 & 100000 & 20 & 2750 & 150 & 150 & 14.23 & 2135 & 2135 & 2250 \\
\hline Beam09 & 200 & 41 & 83 & 71 & 60000 & 12 & 3075 & 128 & 128 & 22.52 & 2883 & 2883 & 983 \\
\hline Beam06 & 200 & 400 & 143 & 131 & 25000 & 5 & 12500 & 150 & 150 & 42.67 & 6401 & 6401 & 563 \\
\hline
\end{tabular}


Template for APEX (Jan. 2014)

Table S2. Size of sputtering crater vs sputtering time.

\begin{tabular}{ccccc}
\hline & \multicolumn{2}{c}{ Correction ON } & \multicolumn{2}{c}{ Correction OFF } \\
\hline $\begin{array}{c}\text { Sputter } \\
\text { time (s) }\end{array}$ & $\begin{array}{c}\text { Deep crater } \\
\text { diameter }(\mathrm{nm})\end{array}$ & $\begin{array}{c}\text { Halo crater } \\
\text { diameter }(\mathrm{nm})\end{array}$ & $\begin{array}{c}\text { Deep crater } \\
\text { diameter }(\mathrm{nm})\end{array}$ & $\begin{array}{c}\text { Halo crater } \\
\text { diameter }(\mathrm{nm})\end{array}$ \\
\hline 0.01 & 19 & - & 19 & - \\
0.1 & 30 & - & 45 & - \\
0.5 & 38 & 84 & 62 & 99 \\
1 & 39 & 98 & 62 & 113 \\
10 & 47 & 171 & 75 & 201 \\
20 & - & 195 & - & 225 \\
30 & - & 199 & - & 253 \\
40 & - & 219 & - & 263 \\
50 & - & 240 & - & 298 \\
60 & - & 244 & - & 315 \\
120 & - & 281 & - & 413 \\
180 & - & 330 & - & 452 \\
240 & - & 371 & - & 458 \\
300 & - & 409 & - & 486 \\
600 & - & 459 & - & 540 \\
\hline
\end{tabular}


Template for APEX (Jan. 2014)
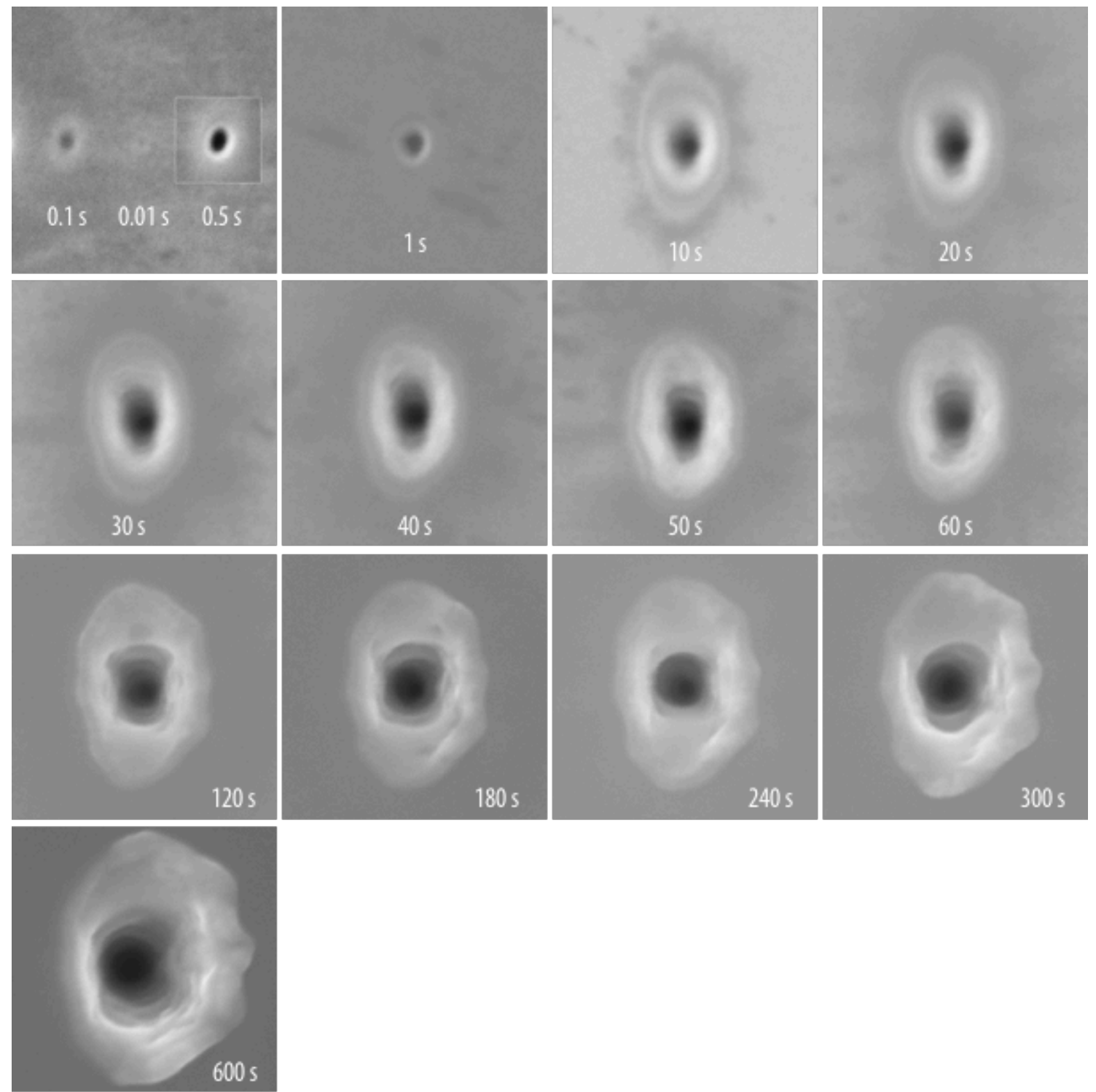

Fig. S1. Secondary electron (SE) images of sputtering craters by a ${ }^{69} \mathrm{Ga}^{+}$primary beam $(20 \mathrm{keV}, 3 \mathrm{pA})$ with aberration corrector for various sputtering times. Image width: $700 \mathrm{~nm}$. 
Template for APEX (Jan. 2014)
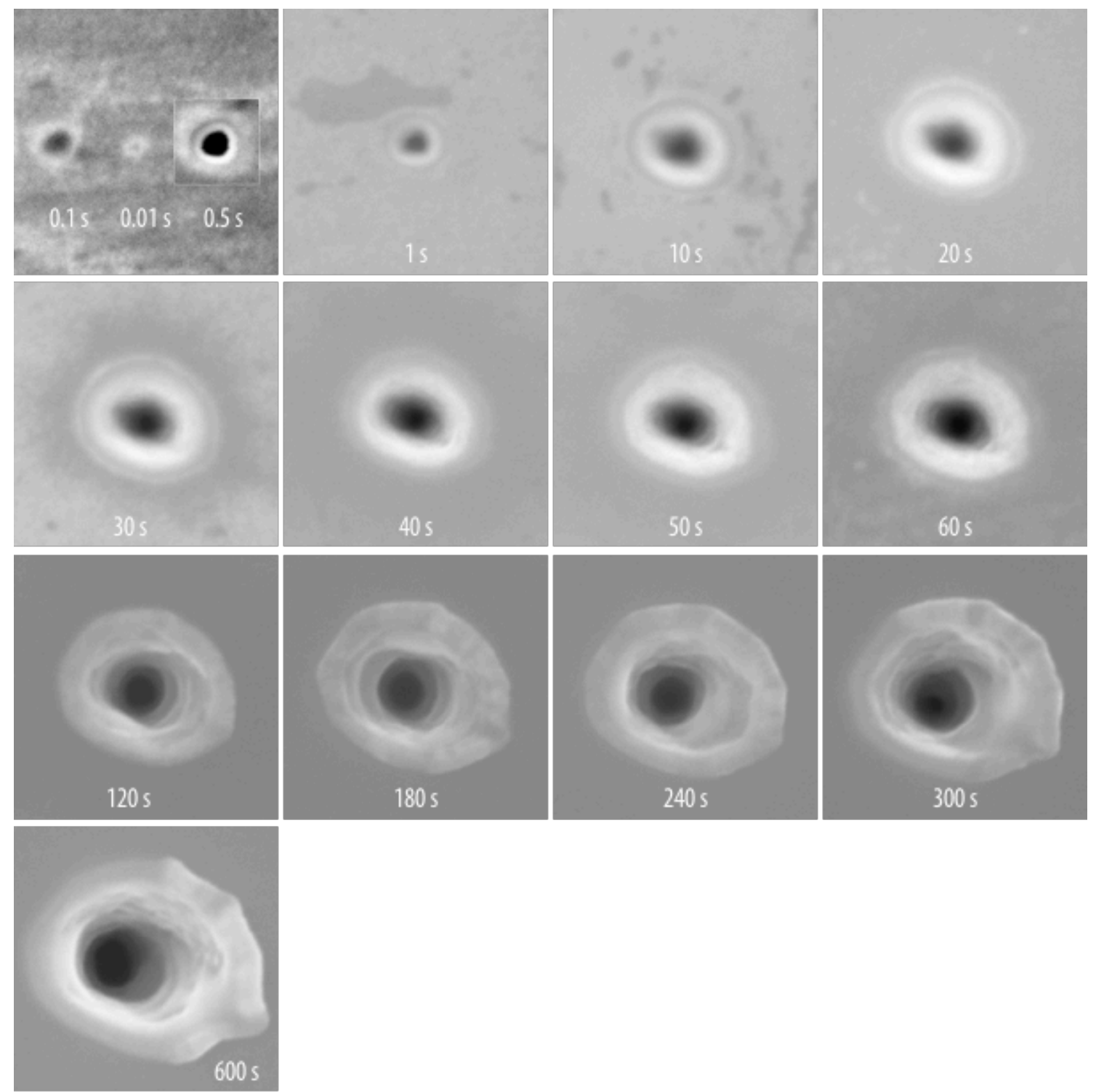

Fig. S2. Secondary electron (SE) images of sputtering craters by a ${ }^{69} \mathrm{Ga}^{+}$primary beam $(20 \mathrm{keV}, 3 \mathrm{pA})$ without aberration corrector for various sputtering times. Image width: $700 \mathrm{~nm}$. 